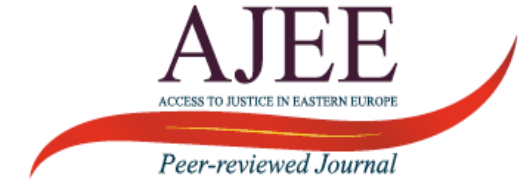

Editorial

\author{
Access to Justice in Eastern Europe \\ ISSN 2663-0575 (Print) \\ ISSN 2663-0583 (Online) \\ Journal homepage http://ajee-journal.com
}

\title{
About Online First Articles and Academic Publishing
}

\author{
Iryna Izarova *1 iD
}

Keywords: digital publishing; sustainable development; open access

\section{Abstract}

Online First Articles was made so that we could publish articles online before they appear in a print issue of AJEE. These articles are fully citable with a DOI, are available for our readers as soon as they are ready and are fully corrected and finalised versions. This way, we can spread knowledge with less delay and help our authors get their work noticed.

Please enjoy this prompt, online access to the latest high-quality content!

\section{INTRODUCTION}

Access to knowledge is an integral part of the modern world, and the dissemination of the results of scientific research is crucial for the development of society.

\footnotetext{
${ }^{1}$ Prof., Dr. Sc. (Law), Editor-in-Chief of Access to Justice in Eastern Europe journal, Law School of Taras Shevchenko National University of Kyiv, Ukraine

Corresponding author, solely responsible for writing and content.

English editing - Dr. Sarah White.

Competing interests: No competing interests were disclosed.

Copyright: (c) 2022 Iryna Izarova. This is an open access article distributed under the terms of the Creative Commons Attribution License, (CC BY 4.0), which permits unrestricted use, distribution, and reproduction in any medium, provided the original author and source are credited.

How to cite: Izarova Iryna About Online First Articles and Academic Publishing 2022 Access to Justice in Eastern

Europe 5(13) 1-2. DOI: https://doi.org/10.33327/AJEE-18-5.1-n000093

Acknowledgement. The author expresses her endless thanks to Dr. Sarah White for her help with this project and its implementation.

Disclaimer: The author declares that her opinion and views expressed in this note are free of any impact of any organizations.
}

First published: 28 Nov 2021 (https://doi.org/10.33327/AJEE-18-5.1-n000093)

Latest published: 


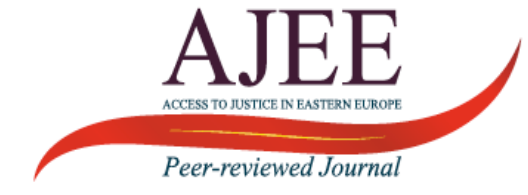

Academic publishing is a process that enables the selection and evaluation of manuscripts of scientific articles for further publication and dissemination among the scientific community of readers.

\section{CHALLENGES AND METHODS OF EVOLUTION}

The length of the publishing process can be extremely negative if there are delays unrelated to ensuring the quality of content, i.e., reviewing and editing manuscripts. Periodicals are published according to the publisher's schedule, so compliance with the terms of preparing publications or turnround is an important point. At the same time, manuscripts can sometimes be delayed by an issue since the number of manuscripts received, the time constraints of reviewers, and general quality varies.

The modern possibilities of publishing online, complete articles are a very attractive phenomenon for all participants in the publication process. Authors whose manuscripts have received positive feedback from reviewers, after finalisation and editing, should not have to wait for the next issue of the publication. Likewise, editors should not be under pressure to adhere to a specific release schedule, and readers, who are the main users of these publications, should have access to the latest research results as soon as possible.

\section{CONCLUDING REMARKS}

Online First Articles are complete, reviewed, and ready for publication, citable with a DOI, and can be used for research. This method of academic publishing seems worth pursuing and implementing in periodicals.

\section{REFERENCES}

What is Online First? What is a DOI, and how is it used?:

https://www.springer.com/gp/authors-editors/editors/what-is-online-first-what-is-a-doi-and-

how-is-it-used-/32910

Online First service:

https://support.springernature.com/en/support/solutions/articles/6000080480-online-first-

service

What is Online First publication?:

https://journals.sagepub.com/page/help/online-first 